\title{
Relation between local restaurant smoking regulations and attitudes towards the prevalence and social acceptability of smoking: a study of youths and adults who eat out predominantly at restaurants in their town
}

\author{
A B Albers, M Siegel, D M Cheng, L Biener, N A Rigotti
}

Tobacco Control 2004;13:347-355. doi: 10.1136/tc.2003.007336

See end of article for authors' affiliations

Correspondence to: Professor Michael Siegel, Social and Behavioral Sciences Department, Boston University School of Public Health, 715 Albany Street, TW2, Boston, MA 02118, USA; mbsiegel@ bu.edu

Received

23 December 2003

Accepted 25 June 2004

\begin{abstract}
Objective: To examine the relation between strength of local restaurant smoking regulations and smoking related social norms among youths and adults.

Design: We used generalised estimating equations logistic regression analysis to examine the relation between regulation strength and youths' and adults' perceptions of adult smoking prevalence and the social acceptability of smoking in their town, while controlling for baseline anti-smoking sentiment in the town.

Setting: Each of the 351 Massachusetts towns were classified as having strong (complete smoking ban), medium (restriction of smoking to enclosed, separately ventilated areas), or weak (all others) restaurant smoking regulations.

Subjects : 1147 Massachusetts youths ages 12-17 years and 2116 adults who reported that they often or always eat out in their own town, drawn from a random digit dial survey.

Main outcome measures: Perceived adult smoking prevalence and perceived social acceptability of smoking in restaurants, in bars, or in general.

Results: Compared to youths from towns with weak regulations, youths from towns with strong regulations were more likely to perceive lower adult smoking prevalence (odds ratio (OR) $1.71 ; 95 \%$ confidence interval (Cl) 1.02 to 2.84 ) and social unacceptability of adult smoking (OR $2.00,95 \% \mathrm{Cl} 1.29$ to 3.08 ) in their town. Adults from towns with strong regulations were not more likely to perceive lower adult smoking prevalence, but had more than twice the odds of perceiving that smoking was unacceptable in restaurants (OR 2.19, 95\% Cl 1.58 to 3.02 ) or bars (OR $2.51,95 \% \mathrm{Cl} 1.90$ to 3.31 ).

Conclusions: Strong local restaurant smoking regulations are associated with favourable smoking related social norms among youths and adults.
\end{abstract}

$\mathrm{T}$ protect the public from the hazards of secondhand smoke exposure in bars and restaurants, ${ }^{1-3}$ many communities have adopted local regulations that restrict smoking in these establishments. ${ }^{4-9}$ Although these regulations are intended to reduce or eliminate secondhand smoke exposure, some have hypothesised that they may have the additional benefit of reducing smoking among youths and adults by altering perceptions of the prevalence and social acceptability of smoking. ${ }^{50-12}$ It is critical to understand whether these laws alter smoking related social norms among youths and adults in order to determine whether they are likely to have an effect on youth smoking initiation or adult smoking cessation behaviour, and if so, to help understand the mechanism for such an effect. Very little is known about the specific effect of local restaurant smoking regulations on smoking behaviour or on smoking related attitudes or social norms that might mediate an effect on smoking behaviour.

There is some evidence, derived from cross sectional econometric or ecological studies, that strong state and local restrictions on smoking reduce smoking participation and consumption among youths ${ }^{13-17}$ or reduce overall smoking prevalence among adults. ${ }^{17-20}$ However, these studies do not control for town level factors that may confound the relation between regulation adoption and smoking behaviour, making it impossible to infer whether or not the regulations caused the reduced smoking or whether states and towns that are more likely to adopt stronger laws are also more likely to have social, political, economic, and demographic characteristics that are themselves the cause of lower smoking rates. These studies also tend to group different smoking restrictions (for example, worksites, schools, restaurants, public places) together and to consider together policies that ban or simply restrict smoking, so that the specific effect of restaurant regulations and the specific effect of varying regulation strength are not known. Most importantly, none of these studies examines factors that may mediate an effect of smoking regulations, such as changes in smoking related attitudes or perceived social norms.

The evidence for an effect of clean indoor air regulations on smoking behaviour would be greatly strengthened if it were shown that: (1) local laws are associated with youth and adult attitudes that are known to influence smoking behaviour, such as the perceived prevalence of smoking in the community ${ }^{11}{ }^{21-30}$ or the perceived social acceptability of smoking in the community ${ }^{1129-31} ;$ (2) that these relations varied according to the strength of local regulation; and (3) that these associations were not explained by town level factors that are most closely related to both adoption of regulations and to smoking related attitudes.

In this paper, we examine the association between local restaurant smoking regulations in Massachusetts and youth and adult attitudes regarding the prevalence and social acceptability of smoking in their communities. Our methodology improves upon existing research by: (1) focusing on 
the relation between smoking regulations and attitudes to establish plausibility for an effect of regulations on behaviour; (2) controlling for baseline social norms regarding smoking in each town, to avoid the potential confounding effect of pre-existing town norms on the relation between regulations and attitudes; and (3) clearly defining and measuring the strength of local restaurant smoking regulations, and comparing regulations of varying strength. To the best of our knowledge, this is the first study to examine the relation between local restaurant smoking restrictions of varying strength and smoking related attitudes among youths or adults in those communities.

Our choice of outcome variables-perceptions of the prevalence and social acceptability of smoking in a respondent's town-was guided by our conceptual hypothesis that local restaurant regulations will: (1) decrease the number of smokers who people observe in a major public setting, thus decreasing the perceived prevalence of smoking in their community; and (2) send a message that smoking is not socially acceptable in that community. ${ }^{12}{ }^{32-34}$ Because we believe that observed smoking behaviour in restaurants and bars is likely to influence perceptions of adult smoking prevalence and social acceptability of adult smoking, the outcome variables we examine focus on respondents' perceptions of adult smoking prevalence in their town and their perceptions of how adults in their town view the social acceptability of smoking in restaurants or of adult smoking in general.

\section{METHODS \\ Sample}

Between January 2001 and June 2002, the Center for Survey Research, University of Massachusetts, Boston, obtained a probability sample of Massachusetts households by random digit dialling as part of a longitudinal study to examine the impact of community based tobacco control interventions on adult and youth smoking behaviour. After conducting a household screening interview with an adult resident, interviewers attempted to survey one adult respondent (ages 18+) and all resident youths between 12 and 17 years of age. Screening interviews were completed with $66 \%$ of sampled households, and 6006 youths were found to be eligible. Parental permission was obtained for $76 \%$ of those eligible and interviews were completed with $84 \%$ of those youths, yielding a final baseline sample of 3862 adolescents. The number of youths interviewed per household was one for $73.9 \%$ of households, two for $23.3 \%$, and three for $2.7 \%$ (but in our final sample, the overwhelming majority of households $(88.2 \%)$ had only one youth respondent, $11.2 \%$ had two respondents, and only $0.6 \%$ had three respondents). Interviews were completed with $70 \%$ of the eligible adult respondents for a total sample size of 6739 adults. The survey oversampled adult smokers, young adults, and recent quitters.

\section{Avoiding contamination bias}

We would not expect local restaurant regulations to affect respondents who are not exposed to them-that is, those who never eat out in restaurants in their town. Also, if respondents eat out a substantial portion of the time at restaurants in other towns, their "exposure" to their own town's regulation may be diluted, and misclassification of exposure status may therefore occur. The problem of contamination bias could occur in two ways: (1) if subjects in a town with stronger regulations sometimes eat out in towns with weaker regulations; and (2) if subjects in a town with weaker regulations sometimes eat out in towns with stronger regulations. In either case, this bias would favour the null hypothesis. We assessed the relative frequency with which respondents eat out in their own town versus other towns with the survey question: "When you go out to eat, how often do you go to restaurants in [TOWN]?" We subsequently restricted our analysis to the 1154 youths and 2139 adults who responded "often or always", excluding from the analyses subjects who stated that they ate out in their own town only "sometimes", "rarely", or "never".

Of the 1154 youths in the sample, 856 (74.2\%) stated that they often went to restaurants in their town and 298 (25.8\%) stated that they always went to restaurants in their town. Of the 2708 youths excluded from the sample, 144 (5.3\%) were excluded because they reported never going out to restaurants anywhere or failed to answer this question, 1182 $(43.6 \%)$ were excluded because they reported only sometimes going to restaurants in their town, 835 (30.8\%) were excluded because they rarely went to restaurants in their town, and $550(20.3 \%)$ were excluded because they reported never going to restaurants in their town.

Of the 2139 adults in the sample, $1536(71.8 \%)$ stated that they often went to restaurants in their town and 603 (28.2\%) stated that they always went to restaurants in their town. Of the 4600 adults excluded from the sample, $323(7.0 \%)$ were excluded because they reported never going out to restaurants anywhere or failed to answer this question, 2028 $(44.1 \%)$ were excluded because they reported only sometimes going to restaurants in their town, 1261 (27.4\%) were excluded because they rarely went to restaurants in their town, and $988(21.5 \%)$ were excluded because they reported never going to restaurants in their town.

\section{Measures}

\section{Town of residence}

Actual town of residence was obtained using the reported zip code. However, to facilitate asking questions about the respondents' town, an attempt was made to ascertain the town of residence from the respondent. We cross referenced the town name used in questioning with the actual town of residence. In seven youth and 44 adult cases the towns did not match, resulting in a final sample size of 1147 youths and 2116 adults.

\section{Strength of local restaurant smoking regulation}

We obtained the local restaurant smoking regulation for each of the 351 cities and towns in Massachusetts in force as of 17 June 2002 (the final survey date), as well as any previous regulations in force during the survey period. ${ }^{35}$ We then classified each regulation into one of three categories based on the degree of protection from secondhand smoke exposure in restaurants: (1) strong regulations-no smoking allowed in restaurants and no variances allowed; (2) medium regulations-smoking restricted to enclosed, separately ventilated areas or smoking not permitted in restaurants but variances allowed; and (3) weak regulations-smoking restricted to designated areas or not restricted. For several towns that banned smoking except in adult only restaurants, we classified the regulation as strong for the youth analyses and medium for adults ( since adults are only partially covered by a smoke-free law). Using the actual town of residence, we linked each respondents' survey data to the strength of local regulation in force in their town on the date of their interview.

\section{Perceived smoking prevalence in town}

Respondents' perceptions of the adult smoking prevalence in their town were classified into two categories based on their response to the question: "About how many of the [TOWN] adults that you know smoke cigarettes?" (youth survey) or "About how many adults in [TOWN] are smokers?" (adult survey). Respondents who answered "very few" or "less than half" were classified as perceiving that less than half of adults in their town smoke (lower level of perceived smoking prevalence), while respondents who answered "about half", 
"more than half", or "almost all" were classified as perceiving that half or more of adults in their town smoke (higher level of perceived smoking prevalence). The rationale for this classification was that there is a true smoking prevalence in a town, and in Massachusetts, it is less than $50 \%$ in every town (about $20 \%$ overall). Thus, a lower level of perceived smoking prevalence corresponds with a correct perception of adult smoking prevalence and a higher level of perceived smoking prevalence corresponds to an incorrect perception of adult smoking prevalence.

\section{Personal acceptability of smoking in restaurants and} bars in town

Respondents' individual opinions about the acceptability of smoking in restaurants or bars were assessed by asking: "In [TOWN] restaurants (or bars and clubs), do you think smoking should be allowed throughout the restaurant (or bar or club), only in special smoking areas, or not at all?" Respondents were characterised as perceiving smoking as "personally unacceptable" in these venues based on their individual opinions if they reported that smoking should not be allowed at all, and as perceiving smoking as "personally acceptable" in these venues otherwise. Youths, however, were only asked the question about smoking in restaurants, not in bars.

\section{Social acceptability of smoking in restaurants and bars in town}

Respondents' perceptions of others opinions about the social acceptability of smoking in restaurants were assessed by asking subjects whether they think most adults in their town would prefer that smoking be allowed throughout the restaurant, only in special smoking areas, or not at all. Respondents were classified as perceiving others in their town as viewing smoking in restaurants as "socially unacceptable" if they reported that most adults in their town would prefer that smoking in restaurants not be allowed at all, and as perceiving other adults as viewing smoking in restaurants as "socially acceptable" otherwise.

\section{Social acceptability of adult smoking in general in town}

Youths only were asked "How do most [TOWN] adults that you know feel about other adults smoking?" Youths were classified as perceiving adult smoking in general as "socially unacceptable" in their town if they responded that adults "disapprove a lot" as opposed to "disapprove a little" or "don't mind".

\section{Potential individual level confounding variables}

From the telephone surveys, we obtained the following variables: (1) age group (12-14 years $v 15-17$ years for youths; 18-44 years $v 45$ years or older for adults), (2) sex, (3) race (non-Hispanic white $v$ other), (4) smoking status (whether respondent ever puffed a cigarette for youths; and current smoking status for adults), and (5) education level of adult household informant (for youths) or adult subject (for adults) (college graduate $v$ not college graduate), and (6) household income $(<\$ 50000 v \geqslant \$ 50000)$. For youths only, we also ascertained the presence of at least one adult smoker in the household and the presence of at least one close friend who smokes. For adults only, we also ascertained marital status (married $v$ unmarried), the presence of children under age 18 in the household (none $v$ one or more), and whether the subject was exposed to a smoke-free worksite policy (smoking not allowed throughout the building $v$ all else).

Potential town level confounding variables

From the Elections Division in the office of the Massachusetts Secretary of State, we obtained the percentage of each town's voters who voted "yes" on Question 1, a 1992 ballot initiative that increased the cigarette tax and created a statewide tobacco control programme. This continuous variable served as a measure of the baseline level of antismoking sentiment in each town before the proliferation of local restaurant smoking regulations in the state. From the 2000 United States Census, we obtained the percentage of white residents and the percentage of youths (age $<18$ years) in each town. Of a large number of town level factors, these three were most strongly related, in a non-collinear fashion, with the strength of local restaurant smoking regulations in Massachusetts. ${ }^{36}$

\section{Data analysis}

Because respondents from the same town may be more similar than respondents from different towns, we used a multilevel analytic method-a generalised estimating equations (GEE) logistic regression model-to estimate the association between strength of smoking regulations and the attitudinal outcomes. This procedure does not assume that each observation is independent but allows that data within town "clusters" may be correlated. In this way, the analysis controls for the effects of both individual and town level factors while concurrently estimating and adjusting for the correlation of responses between subjects living in the same town. The type 1 error rate would be inflated if this correlation was ignored. ${ }^{37}$

For the youth analyses, there was not only clustering of subjects within towns, but also the possibility of clustering within households nested in those towns. Since households are nested within towns, we selected town as the clustering level. The robust, or empirical, standard errors derived from the GEE approach allow that individuals within a town may be differentially correlated. ${ }^{38-41}$ Thus, the GEE results will be valid even though youths from the same household may be more correlated than youths from different households. We therefore used a GEE model and the resulting robust variance estimators since the robust estimator produces consistent point estimates ${ }^{38}{ }^{39}$ and standard errors ${ }^{38-41}$ even if the working correlation matrix is misspecified.

To develop our final multivariate models, we used an iterative model building procedure ${ }^{42}$ that assessed the contribution of each variable to the model in the presence of other covariates (using the Wald test at a significance level of 0.10). Ninety five per cent confidence intervals (CIs) for odds ratios (ORs) were calculated with standard errors estimated by the Wald test. ${ }^{42}$

We used indicator variables to create a category for missing values for each covariate so that the same subset of respondents was examined in each analysis within each outcome variable category.

\section{RESULTS}

The bivariate relation between strength of local restaurant smoking regulations and each outcome variable is shown in table 1, along with unadjusted odds ratios for the regulation effect. Table 2 displays the complete multivariate model results for the youth survey and table 3 displays the complete multivariate model results for the adult survey.

\section{Perceived adult smoking prevalence Youths}

The proportion of youths perceiving a lower adult smoking prevalence was significantly higher in towns with strong regulations (table 1). This association persisted after accounting for significant individual and town-level covariates (OR 1.71, 95\% CI 1.02 to 2.84) (table 2). 
Table 1 Perceived adult smoking prevalence, ${ }^{*}$ acceptability of smoking in restaurants or bars, $\uparrow$ and social acceptability of adult smoking in general $\ddagger$ by strength of local restaurant smoking regulation§ among Massachusetts residents who eat out predominantly in their own town

\begin{tabular}{|c|c|c|c|}
\hline & \multicolumn{3}{|c|}{ Strength of local restaurant smoking regulation $\S$} \\
\hline & Weak (\%) & Medium (\%) & Strong (\%) \\
\hline Total youths $(n=1147)$ & $744(64.9 \%)$ & $231(20.1 \%)$ & $172(15.0 \%)$ \\
\hline Total adults ( $n=2116)$ & $1444(68.3 \%)$ & $422(19.9 \%)$ & $250(11.8 \%)$ \\
\hline \multirow{2}{*}{\multicolumn{4}{|c|}{$\begin{array}{l}\text { Perceived adult smoking prevalence } \\
\text { Perceived prevalence of adult smoking* in town }\end{array}$}} \\
\hline & & & \\
\hline \multicolumn{4}{|c|}{ Youths $(n=1143$ ) } \\
\hline High (half or more) & $51.4 \%$ & $42.0 \%$ & $27.5 \%$ \\
\hline Low (less than half) & $48.6 \%$ & $58.0 \%$ & $72.5 \%$ \\
\hline Odds ratio** (95\% Cl) & 1.00 & $1.25(0.81$ to 1.90$)$ & $2.01(1.20$ to 3.37$)$ \\
\hline \multicolumn{4}{|l|}{ Adults $(n=2026)$} \\
\hline High (half or more) & $56.4 \%$ & $51.2 \%$ & $33.3 \%$ \\
\hline Low (less than half) & $43.6 \%$ & $48.8 \%$ & $66.7 \%$ \\
\hline Odds ratio** $(95 \% \mathrm{Cl})$ & 1.00 & 1.25 (0.85 to 1.84$)$ & $1.96(1.29$ to 2.99$)$ \\
\hline \multicolumn{4}{|c|}{ Personal acceptability of smoking in restaurants and bars $\dagger$} \\
\hline \multirow{2}{*}{\multicolumn{4}{|c|}{$\begin{array}{l}\text { Opinion about smoking in restaurants in townt } \\
\text { Youths }(n=1145)\end{array}$}} \\
\hline & & & \\
\hline Personally acceptable & $47.4 \%$ & $42.0 \%$ & $39.5 \%$ \\
\hline Personally unacceptable & $52.6 \%$ & $58.0 \%$ & $60.5 \%$ \\
\hline Odds ratio** $(95 \% \mathrm{Cl})$ & 1.00 & $1.24(0.84$ to 1.85$)$ & $1.36(0.97$ to 1.91$)$ \\
\hline \multicolumn{4}{|l|}{ Adults $(n=2100)$} \\
\hline Personally acceptable & $57.3 \%$ & $51.1 \%$ & $37.5 \%$ \\
\hline Personally unacceptable & $42.7 \%$ & $48.9 \%$ & $62.5 \%$ \\
\hline Odds ratio** $(95 \% \mathrm{Cl})$ & 1.00 & $1.31(1.00$ to 1.70$)$ & $2.26(1.61$ to 3.18$)$ \\
\hline \multirow{2}{*}{\multicolumn{4}{|c|}{ Opinion about smoking in bars in town $\dagger$}} \\
\hline & & & \\
\hline Personally acceptable & $82.6 \%$ & $81.8 \%$ & $64.4 \%$ \\
\hline Personally unacceptable & $17.4 \%$ & $18.2 \%$ & $35.6 \%$ \\
\hline Odds ratio** $(95 \% \mathrm{Cl})$ & 1.00 & $1.06(0.78$ to 1.44$)$ & $2.67(2.07$ to 3.44$)$ \\
\hline \multirow{3}{*}{\multicolumn{4}{|c|}{$\begin{array}{l}\text { Perceived social acceptability of smoking in restaurants } \dagger \\
\text { Perceived opinion of others (adults) in town about } \\
\text { smoking in restaurants } \dagger\end{array}$}} \\
\hline & & & \\
\hline & & & \\
\hline \multicolumn{4}{|c|}{ Youths $(n=1134)$} \\
\hline Socially acceptable & $73.8 \%$ & $58.3 \%$ & $62.9 \%$ \\
\hline Socially unacceptable & $26.2 \%$ & $41.7 \%$ & $37.1 \%$ \\
\hline Odds ratio** $(95 \% \mathrm{Cl})$ & 1.00 & $2.18(1.51$ to 3.15$)$ & $1.68(1.17$ to 2.43$)$ \\
\hline \multicolumn{4}{|l|}{ Adults $(n=2061)$} \\
\hline Socially acceptable & $54.4 \%$ & $47.4 \%$ & $39.7 \%$ \\
\hline Socially unacceptable & $45.6 \%$ & $52.6 \%$ & $60.3 \%$ \\
\hline Odds ratio** $(95 \% \mathrm{Cl})$ & 1.00 & $1.32(1.05$ to 1.66$)$ & 1.81 (1.39 to 2.37$)$ \\
\hline \multirow{2}{*}{\multicolumn{4}{|c|}{$\begin{array}{l}\text { Perceived social acceptability of adult smoking } \ddagger \\
\text { Social acceptability of smoking by adults in town } \ddagger\end{array}$}} \\
\hline & & & \\
\hline \multicolumn{4}{|c|}{ Youths $(n=1136)$} \\
\hline Socially acceptable & $85.4 \%$ & $84.7 \%$ & $78.1 \%$ \\
\hline Socially unacceptable & $14.6 \%$ & $15.3 \%$ & $21.9 \%$ \\
\hline Odds ratio** $(95 \% \mathrm{Cl})$ & 1.00 & $1.07(0.72$ to 1.59$)$ & $1.69(1.10$ to 2.58$)$ \\
\hline
\end{tabular}

"Having a lower perception of adult smoking prevalence in one's town was defined as responding that "very few" or "less than half" of adults in one's town smoke (compared to "about half", "more than half," or "almost all"). †For personal acceptability of smoking in restaurants or bars, viewing smoking as personally unacceptable was defined as respondents stating that they think smoking in bars or restaurants should not be allowed at all (compared to being allowed anywhere or only in special sections). For perceived social acceptability of smoking in restaurants, viewing smoking as socially unacceptable was defined as respondents stating that they think adults in their town "disapprove a lot" of smoking in restaurants (compared to "disapprove a little" or "don't mind"). \#For perceived social acceptability of adult smoking in general, viewing smoking as socially unacceptable was defined as respondents stating that they think adults in their town "disapprove a lot" of adult smoking (compared to "disapprove a little" or "don't mind").

§Strength of local restaurant smoking regulation was defined as strong if it banned smoking completely in all restaurants with no variances, medium if it banned smoking but allowed variances or restricted smoking to enclosed, separately ventilated areas, and weak if it required only designated smoking areas or did not restrict smoking at all.

"Respondents who responded "often" or "always" to the question "When you go out to eat, how often do you go out to restaurants in [TOWN]?"

**Unadjusted odds ratio that reflects the likelihood of having a perception of lower smoking prevalence or viewing smoking as socially unacceptable, based on bivariate analysis (regulation strength as only covariate) using GEE to account for town level clustering.

$\mathrm{Cl}$, confidence interval.

\section{Adults}

The proportion of adults perceiving a lower smoking prevalence in their town was significantly higher among those living in towns with strong, but not medium, regulations (table 1). However, this bivariate association did not persist in the multivariate model (OR 1.22, 95\% CI 0.84 to 1.77 ) (table 3 ).
Personal acceptability of smoking in restaurants and bars

Youths

There was no association between youths' individual opinions about the acceptability of smoking in restaurants in their town and the strength of local restaurant smoking regulations (table 1 ). 
Table 2 Final youth multivariate model results showing adjusted odds ratios* associated with strength of local restaurant smoking regulationst and all control variables for having a perception of lower adult smoking prevalence in one's town, $\ddagger$ for perceiving smoking in restaurants in one's town as unacceptable, $\S$ and for perceiving that adults in one's town view adult smoking in general as socially unacceptable

\begin{tabular}{|c|c|c|c|c|}
\hline & \multirow{2}{*}{$\begin{array}{l}\begin{array}{l}\text { Perceived adult smoking } \\
\text { prevalenceł }\end{array} \\
\\
\text { Adjusted odds ratios* } \\
(95 \% \mathrm{CI}) \text { for having a } \\
\text { lower perception of adult } \\
\text { smoking prevalence in } \\
\text { one's town } \ddagger\end{array}$} & \multirow{2}{*}{$\begin{array}{l}\text { Personal acceptability of } \\
\text { smoking in restaurants } \$\end{array}$} & \multirow{2}{*}{$\begin{array}{l}\text { Perceived social acceptability } \\
\text { of smoking in restaurants } \\
\text { Adjusted odds ratios* }(95 \% \mathrm{Cl}) \\
\text { for perceiving smoking in } \\
\text { restaurants as socially } \\
\text { unacceptable (based on } \\
\text { perceived opinion of adults } \\
\text { in one's town) } \S\end{array}$} & \multirow{2}{*}{ 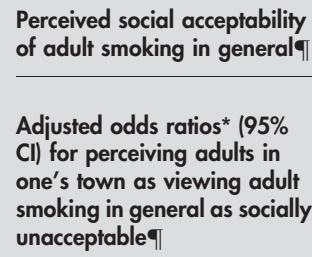 } \\
\hline & & & & \\
\hline \multicolumn{5}{|l|}{$\begin{array}{l}\text { Main predictor variable } \\
\text { Strength of local restaurant smoking } \\
\text { regulationt }\end{array}$} \\
\hline Weak & 1.00 & 1.00 & 1.00 & 1.00 \\
\hline Medium & 1.11 (0.79 to 1.57$)$ & $1.27(0.86$ to 1.86$)$ & 2.30 (1.58 to 3.36$)$ & $1.25(0.87$ to 1.78$)$ \\
\hline $\begin{array}{l}\text { Strong } \\
\text { Individual level control variables }\end{array}$ & 1.71 (1.02 to 2.84$)$ & 1.34 (0.98 to 1.83 ) & 1.61 (1.15 to 2.25$)$ & 2.00 (1.29 to 3.08$)$ \\
\hline \multicolumn{5}{|l|}{ Age } \\
\hline $12-14$ & - & - & - & 1.00 \\
\hline $15-17$ & - & - & - & $0.53(0.36$ to 0.76$)$ \\
\hline \multicolumn{5}{|l|}{ Sex } \\
\hline Male & - & 1.00 & - & - \\
\hline Female & - & 1.43 (1.14 to 1.79$)$ & - & - \\
\hline \multicolumn{5}{|l|}{ Race/ethnicity } \\
\hline Non-Hispanic white & 1.00 & - & - & - \\
\hline Other & $0.71(0.48$ to 1.06$)$ & - & - & - \\
\hline \multicolumn{5}{|l|}{ Smoking status } \\
\hline Experimenter/smoker & 1.00 & 1.00 & - & 1.00 \\
\hline Never smoker & 1.60 (1.14 to 2.23 ) & 1.43 (1.07 to 1.91$)$ & - & $1.82(1.15$ to 2.90$)$ \\
\hline \multicolumn{5}{|l|}{ Peer smoking } \\
\hline No close friends smoke & 1.00 & 1.00 & - & - \\
\hline At least one close friend smokes & 0.75 (0.57 to 0.98$)$ & $0.73(0.55$ to 0.95$)$ & - & - \\
\hline \multicolumn{5}{|l|}{ Household smoking } \\
\hline $\begin{array}{l}\text { No adult smoker in household } \\
\text { Adult smoker in household }\end{array}$ & $\begin{array}{l}1.00 \\
0.35(0.27 \text { to } 0.45)\end{array}$ & $\begin{array}{l}1.00 \\
0.78(0.62 \text { to } 0.98)\end{array}$ & $\begin{array}{l}1.00 \\
0.58(0.45 \text { to } 0.74)\end{array}$ & 1.00 \\
\hline \multicolumn{5}{|l|}{ Education of adult informant } \\
\hline Not college graduate & 1.00 & - & - & - \\
\hline College graduate & 1.57 (1.17 to 2.11$)$ & - & - & - \\
\hline \multicolumn{5}{|l|}{ Household income } \\
\hline$\leqslant \$ 50000$ & 1.00 & - & - & - \\
\hline$>\$ 50000$ & 1.65 (1.19 to 2.29 ) & - & - & - \\
\hline \multicolumn{5}{|l|}{ Town level control variables } \\
\hline \multicolumn{5}{|l|}{$\begin{array}{l}\text { Percentage of town "yes" vote on } \\
\text { Question } 1 \text { (continuous variable) }\end{array}$} \\
\hline \multicolumn{5}{|l|}{$\begin{array}{l}\text { Question } 1 \text { (continuous variable) } \\
\text { Odds ratio corresponding to each }\end{array}$} \\
\hline $\begin{array}{l}10 \text { percentage point increase in } \\
\text { yes vote }\end{array}$ & 1.78 (1.49 to 2.13 ) & - & 1.25 (1.06 to 1.47$)$ & - \\
\hline \multicolumn{5}{|c|}{$\begin{array}{l}\text { Percentage of town residents who are } \\
\text { white (continuous variable) } \\
\text { Odds ratio corresponding to each } \\
10 \text { percentage point increase in } \\
\text { proportion of residents who are }\end{array}$} \\
\hline white & - & - & $0.84(0.78$ to 0.90$)$ & 0.81 (0.74 to 0.89$)$ \\
\hline $\begin{array}{l}\text { Percentage of town residents who are } \\
\text { youths (age }<18 \text { ) (continuous variabl } \\
\text { Odds ratio corresponding to each } \\
10 \text { percentage point increase in } \\
\text { proportion of residents who are } \\
\text { youths }\end{array}$ & 1.48 (0.94 to 2.35$)$ & - & - & 1.53 (1.02 to 2.29$)$ \\
\hline \multicolumn{5}{|c|}{$\begin{array}{l}\text { Cl, confidence interval. } \\
\text { "Adjusted odds ratio reflects final model that included only those variables that contributed significantly to the model, as assessed by a Wald test (with } \alpha=0.10 \text { ). } \\
\text { Odds ratios are derived from a GEE logit model that accounts for clustering among subjects from the same town. Odds ratios are adjusted for all other variables } \\
\text { included in the model. } \\
\text { tStrength of local restaurant smoking regulation was defined as strong if it banned smoking completely in all restaurants with no variances, medium if it banned } \\
\text { smoking but allowed variances or restricted smoking to enclosed, separately ventilated areas, and weak if it required only designated smoking areas or did not } \\
\text { restrict smoking at all. } \\
\text { tHaving a lower perception of adult smoking prevalence in one's town was defined as responding that "very few" or "less than half" of adults in one's town } \\
\text { smoke (compared to "about half", "more than half", or "almost all"). } \\
\text { \$For personal acceptability of smoking in restaurants, viewing smoking as personally unacceptable was defined as respondents stating that they think smoking in } \\
\text { restaurants should not be allowed at all (compared to being allowed anywhere or only in special sections). For perceived social acceptability of smoking in } \\
\text { restaurants, viewing smoking as socially unacceptable was defined as respondents stating that they think adults in their town "disapprove a lot" of smoking in } \\
\text { restaurants (compared to "disapprove a little" or "don't mind"). } \\
\text { "For perceived social acceptability of adult smoking in general, viewing smoking as socially unacceptable was defined as respondents stating that they think adults } \\
\text { in their town "disapprove a lot" of adult smoking (compared to "disapprove a little" or "don't mind"). }\end{array}$} \\
\hline
\end{tabular}


Table 3 Final adult multivariate model results showing adjusted odds ratios* associated with strength of local restaurant smoking regulations $\dagger$ and all control variables for having a perception of lower adult smoking prevalence in one's town, $¥$ for perceiving smoking in restaurants or bars in one's town as unacceptable, $\$$ and for perceiving that other adults in one's town view smoking in restaurants as socially unacceptable

\begin{tabular}{|c|c|c|c|c|}
\hline & \multirow{2}{*}{$\begin{array}{l}\begin{array}{l}\text { Perceived adult smoking } \\
\text { prevalence }\end{array} \\
\text { Adjusted odds ratios* } \\
(95 \% \text { CI) for having a } \\
\text { lower perception of adult } \\
\text { smoking prevalence in } \\
\text { one's town } \neq\end{array}$} & \multicolumn{2}{|c|}{$\begin{array}{l}\text { Personal acceptability of smoking in restaurants } \\
\text { and bars§ }\end{array}$} & \multirow{2}{*}{$\begin{array}{l}\text { Perceived social acceptability } \\
\text { of smoking in restaurants§ } \\
\text { Adjusted odds ratios* } 195 \% \\
\text { Cl) for perceiving adults in } \\
\text { one's town as viewing } \\
\text { smoking in restaurants as } \\
\text { socially unacceptable§ }\end{array}$} \\
\hline & & $\begin{array}{l}\text { Adjusted odds ratios* } \\
(95 \% \mathrm{Cl}) \text { for perceiving } \\
\text { smoking in restaurants } \\
\text { as unacceptable (based } \\
\text { on individual opinion)§ }\end{array}$ & $\begin{array}{l}\text { Adjusted odds ratios* } \\
\text { (95\% Cl) for perceiving } \\
\text { smoking in bars as } \\
\text { unacceptable (based } \\
\text { on individual opinion)§ }\end{array}$ & \\
\hline \multicolumn{5}{|l|}{ Main predictor variable } \\
\hline \multicolumn{5}{|l|}{$\begin{array}{l}\text { Strength of local restaurant smoking } \\
\text { regulationt }\end{array}$} \\
\hline Weak & 1.00 & 1.00 & 1.00 & 1.00 \\
\hline Medium & $1.02(0.71$ to 1.45$)$ & 1.35 (1.02 to 1.79$)$ & 1.02 (0.73 to 1.42$)$ & $1.30(1.05$ to 1.60$)$ \\
\hline Strong & $1.22(0.84$ to 1.77$)$ & $2.19(1.58$ to 3.02$)$ & $2.51(1.90$ to 3.31$)$ & $1.48(1.18$ to 1.86$)$ \\
\hline \multicolumn{5}{|l|}{ Individual level control variables } \\
\hline \multicolumn{5}{|l|}{ Age } \\
\hline $18-44$ & 1.00 & 1.00 & 1.00 & - \\
\hline $45+$ & 1.96 (1.58 to 2.45 ) & $0.71(0.58$ to 0.86$)$ & $1.47(1.17$ to 1.84$)$ & - \\
\hline \multicolumn{5}{|l|}{ Education } \\
\hline Not college graduate & 1.00 & 1.00 & - & 1.00 \\
\hline College graduate & $2.63(2.10$ to 3.28$)$ & $1.31(1.10$ to 1.56$)$ & - & $1.39(1.16$ to 1.66$)$ \\
\hline \multicolumn{5}{|l|}{ Income } \\
\hline$\leqslant \$ 50000$ & - & - & - & - \\
\hline$>\$ 50000$ & - & - & - & - \\
\hline \multicolumn{5}{|l|}{ Race } \\
\hline Non-Hispanic white & 1.00 & 1.00 & 1.00 & - \\
\hline Other & 0.58 (0.46 to 0.73 ) & 1.72 (1.37 to 2.15$)$ & 1.34 (0.99 to 1.82$)$ & - \\
\hline \multicolumn{5}{|c|}{ (1) } \\
\hline Male & 1.00 & 1.00 & - & 1.00 \\
\hline Female & $0.73(0.61$ to 0.87$)$ & 1.21 (1.03 to 1.44$)$ & - & 1.28 (1.09 to 1.51$)$ \\
\hline \multicolumn{5}{|l|}{ Marital status } \\
\hline Not married & 1.00 & 1.00 & - & 1.00 \\
\hline Married & $1.74(1.35$ to 2.25$)$ & 1.19 (0.99 to 1.44$)$ & - & $1.42(1.22$ to 1.65$)$ \\
\hline \multicolumn{5}{|l|}{ Children in household } \\
\hline None & - & 1.00 & 1.00 & - \\
\hline \multirow{2}{*}{\multicolumn{5}{|c|}{$\begin{array}{l}\text { Une or more } \\
\text { Smoking status }\end{array}$}} \\
\hline & & & & \\
\hline Non-smoker (or former smoker) & - & 1.00 & 1.00 & 1.00 \\
\hline Current smoker & - & $0.33(0.28$ to 0.39$)$ & $0.22(0.18$ to 0.28$)$ & $0.82(0.70$ to 0.98$)$ \\
\hline \multicolumn{5}{|l|}{ Worksite smoking policy } \\
\hline All else & 1.00 & - & - & - \\
\hline \multirow{3}{*}{\multicolumn{5}{|c|}{$\begin{array}{l}\text { Strong (complete ban) } \\
\text { Town level control variables } \\
\text { Percentage of town "yes" vote on }\end{array}$}} \\
\hline & & & & \\
\hline & & & & \\
\hline \multicolumn{5}{|l|}{ Question 1 (continuous variable) } \\
\hline $\begin{array}{l}\text { Odds ratio corresponding to each } 10 \\
\text { percentage point increase in yes vote }\end{array}$ & 2.08 (1.72 to 2.51$)$ & - & - & 1.15 (1.04 to 1.27$)$ \\
\hline \multicolumn{5}{|l|}{$\begin{array}{l}\text { Percentage of town residents who are } \\
\text { white (continuous variable) }\end{array}$} \\
\hline $\begin{array}{l}\text { white (continuous variable) } \\
\text { Odds ratio corresponding to each } 10 \\
\text { percentage point increase in proportion }\end{array}$ & 1.17 (1.02 to 1.33$)$ & - & & \\
\hline $\begin{array}{l}\text { percentage point increase in proportion } \\
\text { of residents who are white }\end{array}$ & & & - & - \\
\hline \multicolumn{5}{|l|}{$\begin{array}{l}\text { Percentage of town residents who are youths } \\
\text { (age }<18 \text { ) (continuous variable) }\end{array}$} \\
\hline $\begin{array}{l}\text { Odds ratio corresponding to each } 10 \\
\text { percentage point increase in proportion }\end{array}$ & - & - & & \\
\hline of residents who are youths & & & - & - \\
\hline \multicolumn{5}{|c|}{$\begin{array}{l}\text { *Adjusted odds ratio reflects final model that included only those variables that contributed significantly to the model, as assessed by a Wald test (with } \alpha=0.10 \text { ). } \\
\text { Odds ratios are derived from a GEE logit model that accounts for clustering among subjects living in the same town. Odds ratios are adjusted for all other variables } \\
\text { included in the model. } \\
\text { tStrength of local restaurant smoking regulation was defined as strong if it banned smoking completely in all restaurants with no variances, medium if it banned } \\
\text { smoking but allowed variances or restricted smoking to enclosed, separately ventilated areas, and weak if it required only designated smoking areas or did not } \\
\text { restrict smoking at all. } \\
\text { fHaving a lower perception of adult smoking prevalence in one's town was defined as responding that "very few" or "less than half" of adults in one's town } \\
\text { smoke (compared to "about half", "more than half", or "almost all"). } \\
\text { \$For personal acceptability of smoking in restaurants or bars, viewing smoking as personally unacceptable was defined as respondents stating that they think } \\
\text { smoking should not be allowed at all (compared to being allowed anywhere or only in special sections). For perceived social acceptability of smoking in } \\
\text { restaurants, viewing smoking as socially unacceptable was defined as respondents stating that they think adults in their town "disapprove a lot" of smoking in } \\
\text { restaurants (compared to "disapprove a little" or "don't mind"). }\end{array}$} \\
\hline
\end{tabular}

Adults

Among adults, personal acceptability of smoking in restaurants in their town was significantly related to the strength of local restaurant smoking regulations (table 1 ), and the association between living in a town with a medium (OR
$1.35,95 \%$ CI 1.02 to 1.79 ) or a strong (OR $2.19,95 \%$ CI 1.58 to 3.02) regulation and perceiving smoking in restaurants as unacceptable persisted in the final multivariate model (table 3). Strong, but not medium, regulations were associated with the perception of smoking in bars in one's 
town as being unacceptable (table 1), and this association persisted in the final model (OR 2.51, 95\% CI 1.90 to 3.31 ) (table 3).

\section{Perceived social acceptability of smoking in restaurants \\ Youths}

Perceiving that adults in one's town viewed smoking in restaurants as socially unacceptable was significantly more likely among youths living in towns with medium and strong regulations (table 1 ), and this association persisted in the final multivariate model (OR 2.30, 95\% CI 1.58 to 3.36 for medium regulations and OR 1.61, 95\% CI 1.15 to 2.25 for strong regulations) (table 2 ).

\section{Adults}

Among adults, perceived social acceptability of smoking in restaurants in their town was significantly related to the strength of local restaurant smoking regulations (table 1 ), and the association between living in a town with a medium (OR 1.30, 95\% CI 1.05 to 1.60 ) or a strong (OR 1.48, 95\% CI 1.18 to 1.86$)$ regulation and perceiving smoking in restaurants as socially unacceptable persisted in the final multivariate model (table 3 ).

\section{Perceived social acceptability of adult smoking in general \\ Youths}

Strong, but not medium, regulations were significantly associated with youths' perceptions of how adults in their town viewed the social acceptability of adult smoking (table 1). The increased likelihood of perceiving adult smoking as socially unacceptable in one's town among youths living in towns with strong regulations persisted in the final model (OR 2.00, 95\% CI 1.29 to 3.08) (table 2). It should be noted that despite the significant relation between restaurant smoking regulations and perceived social acceptability of adult smoking among youths, the vast majority of youths in our sample $(84.2 \%)$ still perceived smoking by adults in their town as socially acceptable, even in towns with strong regulations $(78.1 \%)$.

\section{DISCUSSION}

To the best of our knowledge, this is the first paper to examine the association between local restaurant smoking restrictions and smoking related attitudes among youths and adults. We found that among Massachusetts youths and adults who eat out predominantly in their own town, more restrictive local restaurant and bar smoking regulations were significantly associated with higher levels of perceived social unacceptability of smoking in these establishments. Among youths, strong regulations were also significantly associated with lower levels of perceived adult smoking prevalence and with higher levels of perceived social unacceptability of adult smoking in general.

Despite the cross sectional study design, there are several reasons why we believe these observed associations are real, and not a result of confounding or bias. First, the observed associations are not explained by a wide range of potential individual level confounding variables, including demographic factors, individual smoking status, peer and household smoking, and household education and income levels.

Second, the observed associations are not explained by three major potential town level confounders that have been found to be highly correlated with the adoption of stronger local restaurant smoking regulations and could plausibly also affect smoking-related attitudes: the percentage of town's voters who voted for a cigarette tax initiative (Question 1) in 1992 (before the enactment of most local restaurant smoking regulations), the percentage of white residents in the town, and the percentage of youths in the town. ${ }^{36}$ The Question 1 yes vote likely reflects the general level of anti-smoking sentiment in a town and the town specific smoking prevalence, since smokers would be expected to be more likely to vote against an increased cigarette tax.

Third, the associations were observed in a model that accounted for clustering within respondents' town of residence and household. This helps reduce the chances of type I error that could otherwise be introduced if this clustering were ignored.

Fourth, contamination bias has been minimised by restricting the sample to respondents who often or always eat out in their own towns. It is among these subjects that the strength of regulation to which they are exposed could be measured most accurately. Contamination bias, caused by subjects eating out substantially in other towns, would dilute any observed effects of the smoking regulations, and to lessen the strong likelihood of type 2 errors, we felt it important to analyse the sample subset with exposure measured most accurately.

Finally, the observed associations do not appear to be attributable to selection bias that may result from the restriction of the sample to respondents who often or always eat out at restaurants in their own towns. Analyses indicated no substantial differences between our sub-samples and excluded respondents in any of the individual or town level characteristics included in the analyses. We also included all significant individual and town level factors in the models in order to account for any small differences in the distribution of these variables between subgroups. Moreover, any differences between these subgroups would be expected to affect the study's external validity (generalisability) rather than its internal validity.

Although our analyses suggest that the observed cross sectional relation between local restaurant smoking regulations and town social norms is not caused by confounding, we cannot rule out the possibility of a reverse association-in other words, town social norms may influence the adoption of local smoking regulations, rather than the regulations causing changes in the social norms. It is also possible, if not likely, that a reciprocal relationship exists; social norms may influence regulations which may in turn modify or strengthen social norms. ${ }^{33}{ }^{34}$ While analyses of cross sectional data can control for potential confounding variables, there is no analytical way to rule out the possibility of a reverse association. One can only examine the plausibility of a reverse association and use judgment to assess the most likely direction of effect.

There is evidence, from the psychology, sociology, political science, and tobacco control literature, that changes in public policies have a powerful influence on social norms ${ }^{33}$ 44 $^{43-50}$; this influence derives partly from the communication function of formal rules, but also from law's practical authority, enforcement authority, and moral authority. ${ }^{33}$ The literature also demonstrates that some level of preexisting social norms in support of a policy may be necessary to facilitate the enactment of legislation. ${ }^{33} 34441$ Thus, the most likely explanation of our findings is a reciprocal effect of social norms on regulations and of regulations on social norms. As Kagan and Skolnick suggest, "legal enactments can transform norms that are only partly or tentatively institutionalized at the social level into more authoritative and widely institutionalized social norms" and "the law reinforces an already existing normative order". ${ }^{33}$ Smoking restrictions, in particular, have "articulated and legitimated the inchoate norms concerning nonsmokers' 'right' to breath 'clean' air and thereby, accelerated the acceptance of 'no smoking among nonsmokers' as a civility norm". ${ }^{33}$ Through 
the enactment and implementation of clean indoor air regulations, "an emerging cultural norm, still tentatively struggling for authority ... acquires much greater moral force" ${ }^{33}$

To determine the direction of causality (or to assess the strength of the causal link in one direction), a longitudinal study is required, since changes in social norms can then be measured. Since these data represent the baseline of a two year longitudinal study, we plan to use the follow up data to help elucidate the strength and direction of causal effects represented by the cross sectional relations observed in this study.

These findings, if indeed indicative of an effect of smoking regulations on social norms, could have important implications for public health practice and policy. Both perceived smoking prevalence ${ }^{1121-30}$ and the perceived social acceptability of smoking ${ }^{11}$ 29-31 have been shown to be strong predictors of adolescent smoking initiation. If strong local restaurant smoking regulations affect the perceived prevalence and social acceptability of adult smoking among youths who eat out predominantly in their own town, it is plausible that these regulations could ultimately have an effect on smoking initiation among this subset of youths. Since strong anti-smoking community norms may also encourage adult smoking cessation and restaurants and bars are important social venues whose culture is likely to have a substantial impact on these norms, the observed association between local bar and restaurant smoking regulations on perceived social unacceptability of smoking in these venues among adults provide evidence for the plausibility of an impact of such regulations on the perceived social acceptability of smoking in general, and therefore, on cigarette consumption and smoking cessation.

This study has five important limitations. First, the sample was restricted to respondents who reported often or always eating out in their own town when they went to restaurants. Thus, the results are generalisable only to this subset, which in our surveys represented about one third of the population. Nevertheless, this is the population that we would hypothesise to be affected by the regulations.

Second, although we did restrict our sample to respondents who eat out predominantly in their town, there is still a possibility of residual contamination bias. About $74 \%$ of our sample youths and $72 \%$ of adults reported eating out often, but not always, in their own town. There is still the possibility that these respondents' exposure is being obscured somewhat by their dining experiences in other towns. This would create a bias towards the null hypothesis.

Third, it is possible that it could take a long time (perhaps several years) before local restaurant smoking regulations have a measurable effect on attitudes. About $70 \%$ of our youth sample and $46 \%$ of adults lived in towns with regulations in effect for less than two years. Thus, if it were to take two years for a strong local restaurant regulation to have a measurable impact on attitudes, less than one third of the youth and only a little more than half of the adults in our study living in towns with strong regulations would be expected to have been affected by the regulation. This factor would also lead to a bias toward the null hypothesis.

Fourth, we did not have information on compliance with the regulations. Any non-compliance that occurred would essentially create a non-differential misclassification of exposure (blurring the true distinction between towns with $100 \%$ smoke-free restaurants and those without). This factor would favour the null hypothesis.

Finally, as discussed above, since this is a cross sectional analysis, we cannot establish with certainty whether reported perceived prevalence and social unacceptability of smoking were a consequence of the restaurant and bar regulations or

\section{What this paper adds}

There is some evidence, derived from cross sectional econometric or ecological studies, that strong state and local smoking restrictions may reduce smoking prevalence or cigarette consumption among youths and adults. However, these studies do not control for important town level factors (such as baseline levels of anti-smoking sentiment in the town) which may confound the relation between regulation adoption and smoking behaviour and do not examine factors that may mediate an effect of smoking regulations.

To the best of our knowledge, this is the first investigation of the association between the strength of local restaurant smoking regulations and attitudes toward the prevalence and social acceptability of smoking, which may mediate the effect of these regulations on smoking behaviour. We control for baseline levels of anti-smoking sentiment in each town and account for clustering of respondents within towns, thus strengthening our ability to draw causal inferences about the effects of restaurant smoking regulations.

The results of this study demonstrate that strong (complete smoking bans), but not medium (smoking restricted to enclosed, separately ventilated areas), local restaurant smoking regulations are associated with youths' perceptions of the prevalence and social acceptability of smoking, and that strong regulations are also associated with adults' perceptions of the social acceptability of smoking in restaurants and bars. This provides evidence that suggests an effect of these regulations on important smoking related social norms. This study demonstrates a multi-level analytic approach for evaluating the impact of local restaurant smoking regulations that controls for important town level confounders.

whether these attitudes were responsible for implementation of the regulations, or both.

The strength of this study is that it demonstrates a significant association between strong restaurant smoking regulations and anti-smoking attitudes among both youths and adults (who eat out predominantly in their own town) using a multi-level model. Because people often share common characteristics of their town, unobserved town correlations play a role in estimating factors related to antismoking attitudes at the individual level. Failure to model these correlations may lead to erroneous significance tests and confidence intervals. The availability of town residence made possible the use of appropriate multi-level statistical techniques with a large sample and may be useful in other studies on the effects of tobacco control regulations.

In conclusion, our results suggest that local smoking regulations, especially complete restaurant and bar smoking bans, are strongly associated with smoking related social norms among both youths and adults who eat out predominantly in their own town and it is therefore plausible that these regulations may ultimately lead to reduction in youth smoking initiation and adult cigarette consumption and to promotion of adult smoking cessation. Further research is now necessary to assess the directionality of the causal link between regulations and social norms, to confirm these findings in other populations, and to investigate whether these observed changes in attitudes translate eventually into changes in smoking behaviour.

\section{ACKNOWLEDGEMENTS}

This work was supported by grants from the National Cancer Institute, State and Community Tobacco Control Interventions 
Research Grant Program (grant number 5 R01 CA86257-03) and the Flight Attendant Medical Research Institute.

\section{Authors' affiliations}

A B Albers, M Siegel, Social and Behavioral Sciences Department, Boston University School of Public Health, Boston, Massachusetts, USA D M Cheng, Biostatistics Department, Boston University School of Public Health, Boston

L Biener, Center for Survey Research, University of Massachusetts Boston N A Rigotti, Tobacco Research and Treatment Center and Division of General Medicine, Massachusetts General Hospital and Harvard Medical School, Boston

Competing interests statement: There are no competing interests or conflicts of interest for any of the authors. Funding for the research is disclosed in the acknowledgments section above.

Ethics approval: This research was approved by the institutional review boards at the University of Massachusetts, Boston, and the Boston University Medical Center.

\section{REFERENCES}

1 Siegel M. Involuntary smoking in the restaurant workplace: a review of employee exposure and health effects. JAMA 1993;270:490-3.

2 Eisner MD, Smith AK, Blanc PD. Bartenders' respiratory health after establishment of smoke-free bars and taverns. JAMA 1998;280:1909-14.

3 Schofield MJ. Smoking bans in restaurants: who is responsible and who needs protection? Tobacco Control 1995;4:113-4.

4 Siegel M, Carol J, Jordan J, et al. Preemption in tobacco control: review of an emerging public health problem. JAMA 1997;278:858-63.

5 Jacobson PD, Zapawa LM. Clean indoor air restrictions: progress and promise. In. Rabin RL, Sugarman SD, eds. Regulating tobacco. New York: Oxford University Press, 2001:207-44.

6 Siegel $M$. The effectiveness of state-level tobacco control interventions: a review of program implementation and behavioral outcomes. Annu Rev Public Health 2002;23:45-71.

7 National Cancer Institute. State and local legislative action to reduce tobacco use. Smoking and tobacco control monograph no. 11. Bethesda, Maryland: US Department of Health and Human Services, National Institutes of Health, National Cancer Institute, 2000, (NIH Publication No.00-4804.).

8 American Nonsmokers' Rights Foundation. U.S. communities with local tobacco control ordinances: Cumulative totals from the ANR Foundation Local Tobacco Control Ordinance Database ${ }^{\odot}$, May 31, 2002, Berkeley, California:American Nonsmokers' Rights Foundation, 2002.

9 US Department of Health and Human Services. Reducing tobacco use: a report of the Surgeon General. Atlanta, Georgia: US Department of Health and Human Services, Centers for Disease Control and Prevention, National Center for Chronic Disease Prevention and Health Promotion, Office on Smoking and Health, 2000

10 Levy DT, Friend K, Polishchuk E. Effect of clean indoor air laws on smokers: the clean air module of the SimSmoke computer simulation model. Tobacco Control 2001; 10:345-51.

11 Jacobson PD, Lantz PM, Warner KE, et al. Combating teen smoking: research and policy strategies. Ann Arbor, Michigan: The University of Michigan Press, 2001.

12 Glantz SA. Smoke-free restaurant ordinances do not affect restaurant business. Period. Journal of Public Health Management and Practice 1999;5:vi-ix.

13 Chaloupka FJ, Grossman M. Price, tobacco control policies and youth smoking. Cambridge, Massachusetts: National Bureau of Economic Research Working Paper 5740, 1996.

14 Chaloupka FJ, Pacula RL. Sex and race differences in young people's responsiveness to price and tobacco control policies. Tobacco Control 1999;8:373-7.

15 Gruber J, Zinman J. Youth smoking in the U.S.: evidence and implications. Cambridge, Massachusetts: National Bureau of Economic Research Working Paper 7780, 2000

16 Wakefield MA, Chaloupka FJ, Kaufman NJ, et al. Effect of restrictions on smoking at home, at school, and in public places on teenage smoking: cross sectional study. BMJ 2000;321:333-7.

17 Wasserman J, Manning WG, Newhouse JP, et al. The effects of excise taxes and regulations on cigarette smoking. Journal of Health Economics 1991;10:43-64.

18 Emont SL, Choi WS, Novotny TE, et al. Clean indoor air legislation, taxation, and smoking behaviour in the United States: an ecological analysis. Tobacco Control 1993;2:13-17.

19 Stephens T, Pederson LL, Koval JJ, et al. The relationship of cigarette prices and no-smoking bylaws to the prevalence of smoking in Canada. Am J Public Health 1997; 87:1519-21.

20 Rigotti NA, Pashos CL. No-smoking laws in the United States: an analysis of state and city actions to limit smoking in public places and workplaces. JAMA 1991;266:3162-7.
21 Chassin L, Presson CC, Sherman SJ, et al. Predicting the onset of cigarette smoking in adolescents: a longitudinal study. J Appl Soc Psychol 1984; 14:224-43.

22 Chassin L, Presson CC, Sherman SJ. Social psychological contributions to the understanding and prevention of adolescent cigarette smoking. Pers Soc Psychol Bull 1990;16:133-51.

23 Collins LM, Sussman S, Mestel-Rauch J, et al. Psychosocial predictors of young adolescent cigarette smoking: a sixteen-month, three-wave longitudinal study. $J$ Appl Soc Psychol 1987; 17:554-73.

24 Sussman S, Dent CW, Mestel-Rauch J, et al. Adolescent non-smokers, triers and regular smokers' estimates of cigarette smoking prevalence: when do overestimations occur and by whom? J Appl Soc Psychol 1988;18:537-51

25 Bauman KE, Botvin GJ, Botvin EM, et al. Normative expectations and the behavior of significant others: an integration of traditions in research on adolescents' cigarette smoking. Psychological Reports 1992;71:568-70.

26 Iannotti RJ, Bush PJ, Weinfurt KP. Perception of friends' use of alcohol, cigarettes, and marijuana among urban schoolchildren: a longitudinal analysis. Addict Behav 1996;21:615-32.

27 Flay BR, Hu FB, Richardson J. Psychosocial predictors of different stages of cigarette smoking among high school students. Prev Med 1998;27:A9-18.

28 Botvin GJ, Botvin EM, Baker E, et al. The false consensus effect: predicting adolescents' tobacco use from normative expectations. Psychological Reports 1992;70:171-8.

29 US Department of Health and Human Services. Preventing tobacco use among young people. A report of the Surgeon General, 1994. Atlanta, Georgia: Public Health Service, Centers for Disease Control and Prevention, Office on Smoking and Health, 1994, (US Government Printing Office Publication No S/N 017-001-00491-0.).

30 Eisenberg ME, Forster JL. Adolescent smoking behavior: measures of social norms. Am J Prev Med 2003;25:122-8.

31 Rohrbach LA, Howard-Pitney B, Unger JB, et al. Independent evaluation of the California Tobacco Control Program: relationships between program exposure and outcomes, 1996-1998. Am J Public Health 2002;92:975-83.

32 DeFleur ML, Ball-Rokeach S. Theories of mass communication, 5th ed. White Plains, New York: Longman, 1989

33 Kagan RA, Skolnick JH. Banning smoking: compliance without enforcement. In: Rabin RL, Sugarman SD, eds. Smoking policy: law, politics, and culture. New York: Oxford University Press, 1993:69-94

34 Opp K. When do norms emerge by human design and when by the unintended consequences of human action? The example of the no-smoking norm. Rationality and Society 2002;14:131-58.

35 Skeer M, Siegel M. The descriptive epidemiology of local restaurant smoking regulations in Massachusetts: an analysis of the protection of restaurant customers and workers. Tobacco Control 2003;12:221-6.

36 Skeer M, George S, Cheng DM, et al. Town-level characteristics and smoking policy adoption in Massachusetts: are local restaurant smoking regulations fostering disparities in health protection? Am J Public Health 2004:94:286-92.

37 Hedeker D, Gibbons RD, Flay BR. Random-effects regression models for clustered data with an example from smoking prevention research.J Consult Clin Psychol 1994:62:757-65.

38 Liang KY, Zeger SL. Longitudinal data analysis using generalized linear models. Biometrika 1986;73:13-22.

39 Pendergast JF, Gange SJ, Newton MA, et al. A survey of methods for analyzing clustered binary response data. International Statistical Review 1996:64:89-118.

40 Stata Corporation. Stata reference manual, release 7: volume 4 Su-Z. College Station, Texas: Stata Press, 2001

41 Horton NJ, Lipsitz SR. Review of software to fit generalized estimating equation regression models. The American Statistician 1999;53:160-9.

42 Hosmer DW, Lemeshow S. Applied logistic regression. New York: John Wiley \& Sons, Inc, 1989.

43 Salazar LF, Baker CK, Price AW, et al. Moving beyond the individual: examining the effects of domestic violence policies on social norms. Am J Community Psychol 2003;32:253-64.

44 Bohannon P. Introduction. In: Bohannon P, eds. Law and warfare. Garden City, New York: Natural History Press, 1967.

45 Ostrom E. Collective action and the evolution of social norms. Journal of Economic Perspectives 2000;14:137-58.

46 Wagenaar AC, Molnar $\sqcup$, Margolis LH. Characteristics of child safety seat users. Accident Analysis \& Prevention 1988;20:311-22.

47 Byrd JC. Environmental tobacco smoke. Medical and legal issues. Med Clin North Am 1992;76:377-98.

48 Klassen TP, MacKay JM, Moher D, et al. Community-based injury prevention interventions. Future of Children 2000:83-110.

49 Jacobson PD, Wasserman J. The implementation and enforcement of tobacco control laws: policy implications for activities and the industry. Journal of Health Politics 1999;24:567-98.

50 Gostin LO, Burris S, Lazzarini Z. The law and the public's health: a study of infectious disease law in the United States. Columbia Law Review 1999;99:59-128

51 DeJong $\mathrm{W}$. The role of mass media campaigns in reducing high-risk drinking among college students. Journal of Studies on Alcohol (Supplement) 2002; 14:182-92. 